\title{
CDD: 581.6 \\ BOTÂNICA ECONÔMICA, UMA CIÊNCIA IMPORTANTE PARA A REGIÃO AMAZÔNICA
}

Ghillean T. Prancel

\begin{abstract}
RESUMO -A botânica econômica é uma ciência atualmente muito importante na região amazônica $e$ deve ser adaptada às necessidadès regionais. Neste trabalho, são fornecidos dados sobre o banco genético da floresta amazônica, espécies e dados econômicos da floresta de extração, sistemas agroflorestais, aproveitamento de monoculturas, naturais e cultivo das várzeas. É necessário um forte programa de botânica econômica para criar sistemas de uso racionais da floresta amazônica.
\end{abstract}

Palavras-chave: Botânica Econômica, Sistemas Agroflorestais, Cacau, Borracha.

\begin{abstract}
The important contribution to be made by the science of Economic Botany in today's Amazonia environment is emphasized. Economy Botany must be tailored to the current situation where and uneccesary destruction is taking place. Studies are needed of the gene pool os useful plants and their wild relatives that occur in the forest; of products suitable for extraction from the forest; of agroforest, systems; os natural monospecific stands of such species as Orbignya phalerata and Mauritia flexuosa; and of plants suitable for cultivation on the várzea. The need for a strong programme in Amazonian Economic Bot any is stressed.

Key words: Economic Botany, Agroforests Systems, Cacau and Rubber Trees.
\end{abstract}

\section{Introdução}

A botânica econômica é uma ciência abrangente e multidisciplinar que tem fornecido muitos dados sobre as plantas úteis do mundo e da região amazônica. Com a destruição atual que foi enfatizada no simpósio sobre "Ocupação da Amazônia e conservação da natureza", a botâníca tem se tornado cada vez mais importante para promover o desenvolvimento racional e a conservação da floresta amazônica. É essencial aumentar o estudo de plantas úteis. Botânica econômica bem sucedida é feita em equipe interdisciplinar com botânicos, ecologistas, antropólogos, químicos, nutricionistas etc. Neste trabalho, apresentamos alguns dados obtidos pelo Instituto de Botânica Econômica de Nova Iorque. Mostraremos alguns dados sobre doze produtos amazônicos bem conhecidos e, a seguir, dados sobre pesquisas recentes da ciência Botânica Econômica.

\section{Algumas Plantas Econômicas da Região Amazônica.}

Em 1987, analisamos junto com os alunos do curso de pós-graduação do INPA, Manaus, os dados sobre as plantas econômicas comercializadas através da zona franca de Manaus. Encontramos onzè classes de produtos importantes ((Tabela 1), com um valor total acima de um bilhão de dólares, em 1985.

Dos onze produtos, dois são provenientes principalmente de plantações: cacau e guaraná; os outros são de espécies selvagens da floresta amazônica.

A extração destrói algumas espécies de madeira, como sorva, pau-rosa e maçaranduba e cinco produtos são de extração sem destruir a árvore: castanha, piaçaba, cumaru, copaíba e balata. Na região, existe outro produto de extração muito importante, a borracha, extraída de duas espécies do gênero Hevea.

O uso de produtos de extração e de outras espécies amazônicas em plantações é um forte argumento para a conservação da floresta amazônica. Além das espécies úteis, existem

\footnotetext{
${ }^{1}$ Royal Botanic Gardens, Kew Richmond, Surrey, TW9 3AB.
} 
outras espécies selvagens no mesmo gênero. As espécies selvagens são importantes para a futura viabilidade das espécies econômicas.

O banco genético da floresta amazônica

A floresta amazônica é uma fonte importante de espécies de plantas úteis, por exemplo: borracha, cacau, castanha, guaraná, mogno, pau-rosa e sorva (Tabela 1). Cada produto vem de uma espécie botânica, mas nas matas há muitas espécies aproveitáveis. Por exemplo, a borracha é extraída de duas espécies do gênero Hevea, H. brasiliensis e H. benthamiana, mas na região há dez espécies do gênero. Cacau é a espécie Theobroma cacau (Figura 1) e o cupuaçu é Theobroma grandiflorum, mas há outras espécies do gênero Theobroma espalhadas na mata. Para o melhoramento das espécies úteis, é necessário o material genético das espécies selvagens. Por exemplo, há espécies selvagens de Hevea resistentes à ferrugem das folhas (Microcyclus ulei) e espécies selvagens do gênero Theobroma resistentes à vassoura-de-bruxa (Marasmus perniciosus). Existem 150 espécies de Paullinia, o gênero do guaraná. Para assegurar o futuro de algumas das espécies vegetais mais importantes, as espécies selvagens são essenciais e elas não vão sobreviver em áreas desvastadas. Por isso, precisamos de muito mais planejamento para reservas e parques na região amazônica. Porque muitas espécies silvestres estão restritas a áreas pequenas, é fácil causar extinção na região, como por exemplo duas espécies do gênero Hevea, H. paludosa e $\mathrm{H}$. rigidifolia, que são endêmicas em áreas pequenas. Para a preservação destas espécies próximas da seringueira, é necessário que exîstam reservas nas áreas onde ocorram as espécies selvagens (Figura 2). No momento, nós não temos reservas biológicas suficientes na região e não há planejamento suficiente para reservas, baseadơ nas distribuições de plantas importantes para o futuro das espécies economicamente de valor.

Tabela 1- Resumo das exportações de produtos vegetais em 1985 Zona Franca de Manaus. Os valores são somente de exportação e não incluem o mercado nacional.

\begin{tabular}{lrlr}
\hline PRODUTO & Valor $(\$) 1985$ & \multicolumn{2}{l}{ Modo de Produção } \\
\hline Cacau & 778.212 .352 & Plantação & \\
Madeira & 169.536 .947 & Extração & D \\
Sorva & 28.749 .587 & Extração & D \\
Castanha & 25.539 .505 & Extração & \\
Guaraná & 3.735 .239 & Plantação & \\
Pau rosa & 938.065 & Extração & D \\
Piaçaba & 474.745 & Extração & \\
Cumaru & 365.024 & Extração & \\
Óleo de Copaíba & 125.426 & Extração & \\
Maçaranduba & 12.425 & Extração & \\
Balata & 10.151 & Extração & \\
\hline
\end{tabular}

TOTAL \$1.014.106.546

D - Destrói a árvore na coleta. 


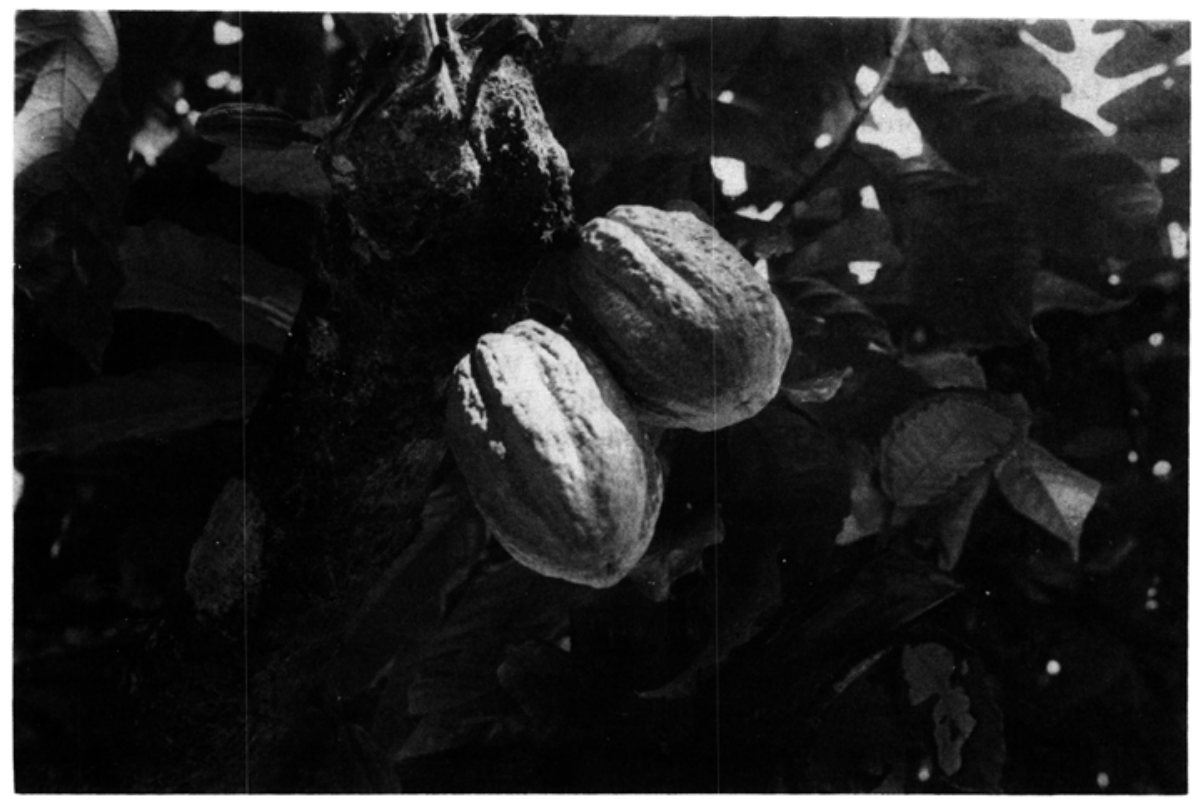

Figura 1. Cacau - Theobroma cacau: Uma espécie amazônica de grande importância econômica.

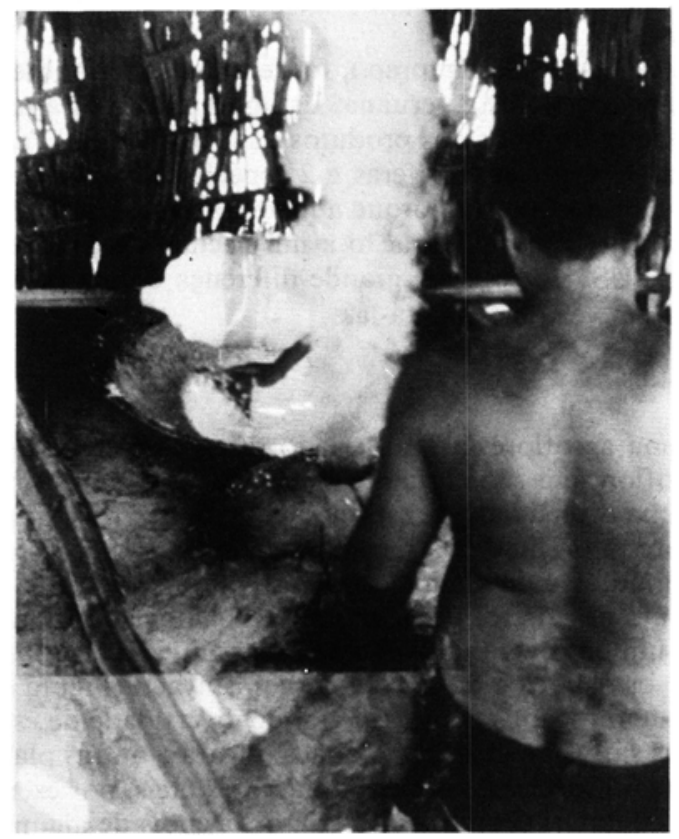

Figura 2. A borracha é uma espécie ainda importante para extração da floresta amazônica. 


\section{Extração}

Desde a descoberta da região amazônica, a extração de produtos foi sempre importante. Outro caminho para o futuro é uma maior extração sem destruir a floresta. Atualmente, temos dois produtos de extração de alta importância na economia regional, a castanha e a borracha; porém, existem muitas outras possibilidades.

Existe abundância de plantas úteis na mata amazônica. Um estudo feito por um pesquisador do Jardim Botânico de Nova Iorque, Brian M. Boom, entre os índios Chácobo, forneceu resultados interessantes. Foi feito um inventário florestal de um hectare nas matas dos Chácobo, na Bolívia. Os índios aproveitam $75(82 \%)$ das 91 espécies de plantas no hectare. Há 649 árvores no hectare, das quais os índios aproveitam 619 (95\%) (Boom 1985 a, b; 1987). Outro estudo feito por William Balée, em colaboração com o Museu Paraense Emílio Goeldi, entre os índios Tembé, no Pará, mostrou que eles usam $100 \%$ das árvores e cipós do hectare inventariado. Assim, as plantas das matas amazônicas têm muitos usos.

Desde muitos anos atrás, houve bastante extração de produtos da mata amazônica pela população brasileira, por exemplo: borracha, castanha, óleo de copaíba, cumaru, sorva e óleo de andiroba. São produtos extraídos sem destruir a floresta. Hoje, face à permanente destruição da mata, existe um movimento dos seringueiros nos Estados do Acre e Rondônia para criar "matas de extração". Achamos que é uma boa idéia porque a mata está produzindo sem desmatamento. Atualmente, os principais produtos de extração com um bom mercado são a borracha e a castanha. Precisamos de pesquisas para descobrir outros produtos de extração para tornar a mata mais rendosa. Também precisamos de pesquisas para criar um mercado para outros produtos. $O$ rendimento de uma mata de extração baseado na borracha e na castanha já é quase igual ao da pastagem de gado na terra firme (Schwartzmann 1987) e com mais produtos, pode até exceder. Devemos criar áreas grandes de extração junto com pesquisas para melhorar o rendimento da extração.

Recentemente (Peters, et al., em prep.), foi feito um estudo interessante sobre o valor atual de um hectare da floresta peruana. Estimaram o valor atual de US\$ 6.820 por ano por hectare baseado no valor dos produtos de lucro líquido. Foram encontradas 60 espécies de madeira, 11 espécies frutíferas e 2 espécies de seringueira. Frutos de látex somaram $90 \%$ do valor da floresta porque a madeira foi calculada com base no tempo gasto para sua produção. Em comparação a um hectare de gado no mesmo tempo, o valor observado é de US\$ 2.960. Esta grande diferença é uma razão para a utilização racional da floresta em vez de desmatá-la.

Sistemas agroflorestais

O termo "sistema agroflorestal" foi criado recentemente na década de 70 , mas o uso de métodos agroflorestais são antigos e começaram quando se iniciou a agricultura. São sistemas com uma diversidade de espécies de árvores, arbustos e ervas que se parecem mais com a floresta original. Na região amazônica, são os sistemas de agricultura de muitas tribos de índios e de alguns caboclos.

No Departamento de Loreto, Peru, existem trabalhos importantes sobre dois sistemas agroflorestais, um entre os índios Bora (Denevan et al. 1984; Denevan \& Padoch 1988) e outro sobre os caboclos da cidade de Tamshiyacu (Figura 3).

Os índios Bora têm roçados com uma grande diversidade de espécies intercaladas. Depois das primeiras safras de mandioca, abacaxi, cará e outras plantas primárias, eles deixam crescer diversas espécies de arbustos e árvores úteis, por exemplo, mapati (Pourouma cecropiifolia) e umari (Poraqueiba sericea). Depois de alguns anos, no lugar de um roçado abandonado, os Bora têm uma mata com plantas úteis, que fornecem frutos, 
remédios, fibras, etc.

Os caboclos ribeirinhos da cidade de Tamshiyacu têm um sistema parecido ao dos índios, com as mesmas espécies. Existe um grande mercado para alguns dos frutos, como mapati e umari, na cidade de Iquitos. Também neste sistema, é plantada a castanheira (Bertholletia excelsa), que produz castanhas após doze anos. A floresta útil é deixada mais ou menos 35 anos e depois é derrubada para reiniciar o sistema. Diversas árvores, por exemplo o umari, são aproveitadas para produzir carvão, e a madeira das castanheiras é utilizada na construição de casas etc. Assim, toda a produção é aproveitada e não queimada. $\mathrm{O}$ fato mais surpreendente é que a renda média de uma família situa-se na faixa de cinco mil dólares por ano. Atualmente, o sistema de Tamshiyacu está na segunda etapa e parece um sistema muito mais sustentável do que os pastos de gado da terra firme.

Sistemas agroflorestais se parecem muito mais com a ecologia natural da região porque são baseados na diversidade. Há muito menos perigo de pragas porque não é monocultura e também há muito menos erosão porque é um sistema florestal com árvores e arbustos para proteger o solo.

Os estudos de sistemas agroflorestais estão ainda no início, mas existem outros estudos sendo feitos, por exemplo, por Anthony Anderson, do Museu Goeldi, sobre os sistemas agroflorestais da Ilha do Marajó, na região do açaí. Lá, também existem sistemas permanentes que rendem bem (Anderson, com. pess.). Porém, precisamos de muito mais pesquisas para criar sistemas agroflorestais na região. Achamos que estas pesquisas devem ser prioridade para a Amazônia. Um bom resumo da ciência agroflorestal está em Altieri (1987).

Aproveitamento de monoculturas naturais

Ecologistas, com bastante razão, são sempre críticos quanto ao uso de monocultu-

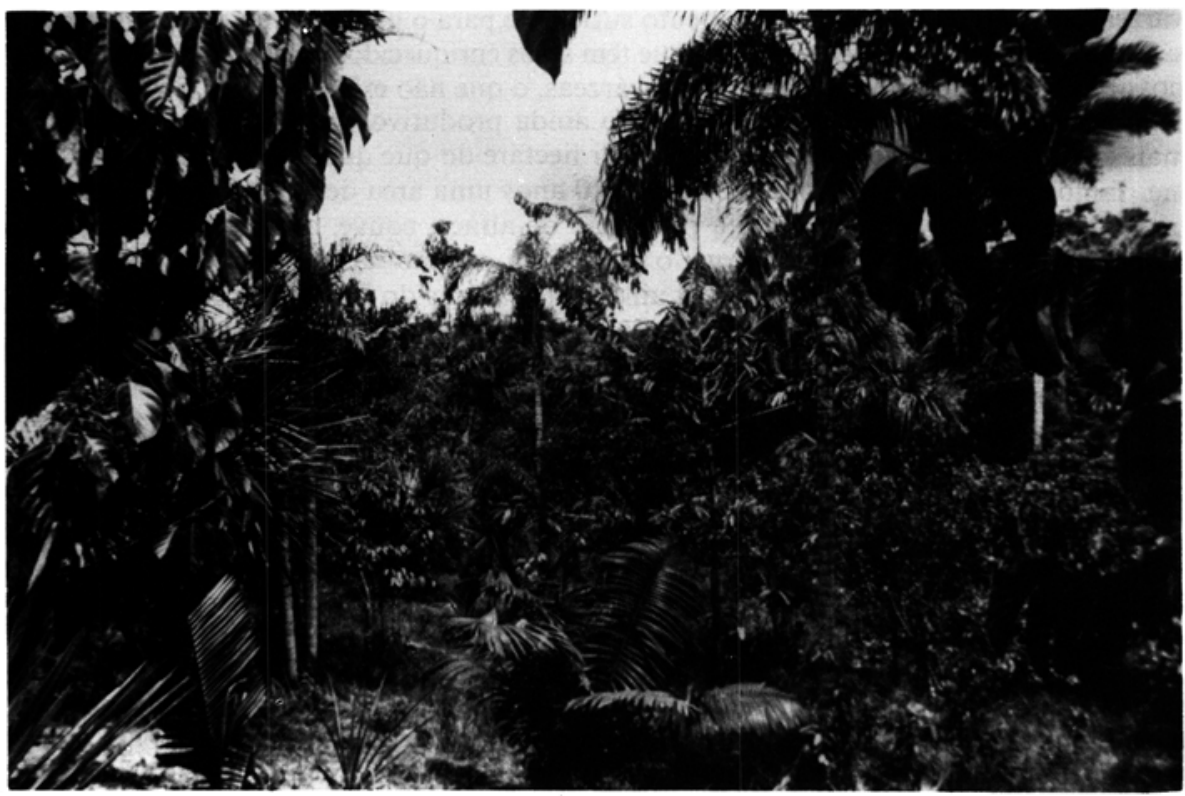

Figura 3. Sistema agroflorestal dos habitantes da cidade de Tamshiyacu, Peru: Área de três anos de idade. 
ras na região da floresta tropical. Porém, existem áreas de grande extensão dominadas por uma espécie, as monoculturas naturais. Por exemplo, recentemente visitamos o Rio Jutaí, afluente do Rio Solimões, onde há uma área de mais de 10 mil hectares de buriti (Mauritia flexuosa), uma espécie de palmeira com muitos usos. O fruto produz óleo e vitamina A, que são muito aproveitados na Amazônia peruana, e as folhas servem para cobrir casas e produzem uma fibra muito utilizada no Estado do Maranhão. Há uma grande indústria do artesanato de buriti na região de Barreirinhas, MA. A monocultura natural mais conhecida, e também intensificada pelo desmatamento, é o babaçu, que talvez seja a espécie com mais usos na região amazônica. $\mathrm{O}$ babaçu produz óleo combustível e comestível, sabão, ração para gado, carvão, lenha para as fábricas de São Luís, farinha, álcool, etc. Existem grandes extensões de babaçu; esta é uma planta com grande potencial e devemos estimular mais pesquisas sobre o seu aproveitamento e melhoramento.

Pesquisadores do Jardim Botânico de Nova Iorque estão estudando uma espécie da família da goiaba (Myrtaceae), o "cam-camu" (Myrciaria dubia), que tem um conteúdo de vitamina $C$ trinta vezes maior do que a laranja. Camu-camu é um arbusto do igapó de águas pretas e das margens de lagos. Existem grandes extensões de camu-camu ou em monocultura natural ou com outras poucas espécies. Outras monoculturas naturais incluem áreas de açaí (Euterpe oleracea), no Pará, e de inajá (Maximilliana).

As plantas nas monoculturas naturais sobrevivem em plantações naturais sem problemas de pragas. Então, devem também ser prioridade para pesquisas e aproveitamento. Interessante é que muitas plantas em monoculturas naturais são úteis, e a maioria tem diversos usos.

\section{Cultivo das várzeas}

Há muitos anos, o grande cientista da Amazônia, Felisberto Camargo (1951), destacou a importância das várzeas para a região amazônica. Existem alguns projetos nas várzeas, mas ainda não há planejamento suficiente para o uso máximo destas áreas, que são muito diferentes da terra firme porque têm solos enriquecidos pelas inundações anuais, possibilitando o cultivo permanente nas várzeas, o que não existe na terra firme. Conhecemos pastos de gado na Ilha do Carneiro ainda produtivos, mesmó após 25 anos ou mais e também com muito mais cabeças por hectare do que qualquer pasto da terra firme. Também visitamos durante os últimos 10 anos uma área de produção de hortaliças perto de Iranduba, ainda com alta produção de alface, couve, cebolinha etc. Também há animais mais apropriados do que o gado para criação nas várzeas, por exemplo, a capivara (Ojasti 1973; Silva 1986), e a anta. Nas várzeas do Marajó, o búfalo já substituiu o gado porque é um animal adaptado às áreas pantanosas. Por que usamos o gado quando existem tantos animais regionais mais adequados para a criação, como anta, a capivara, o veado etc.?

Precisamos desenvolver muito mais as várzeas, mas, por outro lado, há diversas contra-indicações importantes. Há espécies de plantas e animais endêmicos nas várzeas o que não existem na terra firme, por exemplo, a madeira virola (Virola surinamensis), a seringueira verdadeira (Hevea brasiliensis) e o açacu (Hura crepitans). Então, o uso de toda a várzea causará a extinção de muitas espécies. Precisamos, também, de reservas biológicas nas várzeas para preservar as espécies, mas ainda não existem grandes reservas nestas áreas. Pesquisas no INPA, de Manaus, no Museu Paraense Emílio Goeldi, de Belém, e de Michael Goulding (1980) mostram a interdependência entre muitas espécies de peixes e a mata de várzea. Durante as enchentes, os peixes, como por exemplo, o delicioso tambaqui, entram na várzea para comer frutos e folhas. Então, para a conservação do pescado, que é a fonte mais importante de proteína da região, também é necessário preservar grandes extensões de mata de várzea. Nas áreas cultivadas, podemos também plantar árvores importantes para a alimentação dos peixes, como por exem- 
plo, a seringueira; dos mamíferos aquáticos (p. exp. piranha preta) que consome o jauari (Astrocaryum jauari), uma palmeira útil. Pode ser cultivado também a andiroba (Carapa guianensis), fonte de óleo e madeira-de-lei para o homem. Assim, nas várzeas, precisamos de um programa bem planejado de desenvolvimento e de conservação em reservas ecológicas e parques nacionais e estaduais.

\section{Intensificação}

Outro caminho para evitar a destruição desnecessária da floresta é a intensificação da agricultura. Vamos dar apenas o exemplo do tomate na região amazônica. Visitamos um projeto do governo na região de Iranduba, onde havia tomates plantados, porém com as plantas infestadas por pragas como o fusarium, e com baixa produção: menos de meia tonelada por hectare.

Também visitamos a produção de tomates da escola Adventista, na estrada ManausItacoatiara, km 85, e lá achamos uma produção de 53 toneladas por hectares! (Figura 4). Por que a diferença? Porque no sistema adventista há intensificação: usam o mesmo solo da região, mas com controle para matar as pragas e um teto de plástico para reduzir a intensidade da luz. O sistema tem mais despesas com adubos químicos e inseticidas, mas a produção rende bastante para compensar estas despesas. O sistema é importante porque ele usa uma área 106 vezes menor para a mesma produção! Não é necessário derrubar uma grande área de mata para abastecer a cidade de Manaus com tomates! Seguramente, existem possibilidades para a intensificação da agricultura de muitos outros produtos, como alface, cebolinha etc. A intensificação é feita através de diversos caminhos, métodos de cultivo, no caso de tomates, mas também através do fitomelhoramento do material genético para criar variedades com alta produção.

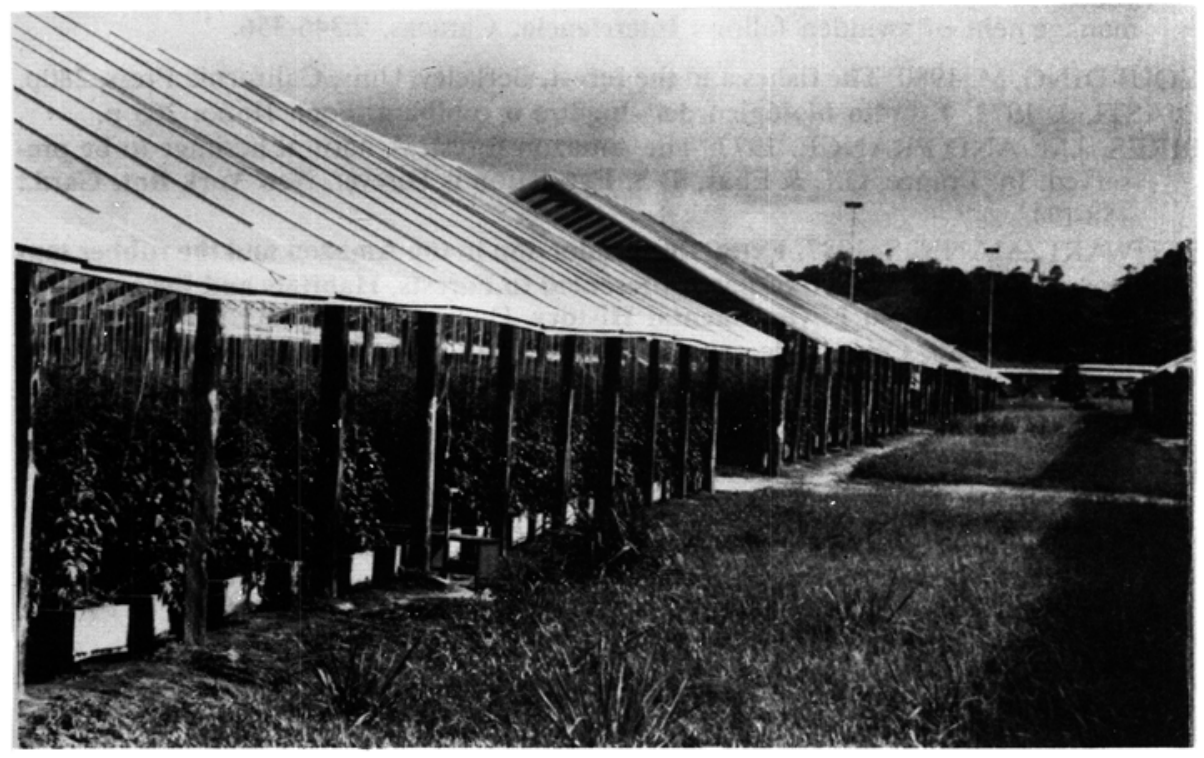

Figura 4. O sistema de cultivo de tomates da escola Adventista, Manaus. 


\section{Conclusões}

A futura existência da floresta amazônica depende de um equilíbrio entre conservação e utilização da floresta. Só alcançaremos esta meta se tivermos, na região amazônica, um forte programa de botânica econômica. Precisamos de muitos outros trabalhos dos tipos apresentados aqui para criar sistemas de uso racionais da floresta e para convencer os políticos que a mata é algo de muito mais valor do que as áreas desmatadas. Assim, precisamos de trabalhos com dados botânicos e dados econômicos. Trabalhos sem estudos econômicos e sociais não servem para mudar idéias políticas.

\section{Referências Bibliográficas}

ALTIERI, M. 1987. Agroecology: The scientific basis of alternative agriculture. Boulder, Westview. Press 227 p.

BOOM, B.M. 1952a. Amazon Indians and the forest environment. Nature 314:324.

BOOM, B.M. 1985b. "Adocacy botany" for the Neotropics. Garden 9 (3):24-32.

BOOM, B.M. 1987. Ethnobotany of the Chácobo Indians, Beni, Bolívia, Adv. Econ. Bot.

CAMARGO, F.C. 1951. Reclamation of the Amazon flood-lands near Belém. In: proceedings of the U.N. Scientific conference on the conservation and Utilization of Resources (Lake Success, New York, 17 August to 6 Sept 1949). Land Resources, New York, p. 598-602.

DENEVAN, W.M. \& PADOCH, C. 1988. Swidden fallow agroforestry in the Peruvian Amazon. Adv. Econ. Bot. 5.

DENEVAN, W.M.; TREACY, J.M.; ALCORN, J.B.; PADOCH, C.; DENSLOW, J. \& PAITAN, S.F. 1984. Indigenuos agroforestry in the Peruvian Amazon: Bora Indian management of swidden fallows Interciencia. Caracas, 9:346-356.

GOULDING, M. 1980. The fishes and the forest. Berkeley, Univ. California Press, 280p. OJASTI, J. 1973. Estudio biológico del chigüire o capibara. Fona IIapo. 265 p.

PIRES, J.M. AND PRANCE. 1977. The Amazon forest: A natural heritage to be preserved. In: Prance, G.T. \& Elias, T. S. Extinction is Forever. New York Bot. Gard.: 158-194.

SCHWARTZMANN, S. 1987: Extractive production in the Amazon and the rubber tapper's movement. Mimeo of paper presented to Forests, Habitats and Resources. A conferencè in Wold Environmental History. Ducke University.

SILVA, L.F.W. 1986. Criação de capivaras em cativeiro. São Paulo, Ed. Nobel 69p. 